\title{
Queries of Parents Related to their Children's Oral Health in Rural and Urban Area of Jaipur: A Clinical Study
}

\author{
Khushboo Rathore ${ }^{1}$, Sandeep Tandon ${ }^{2}$, Meenakshi Sharma ${ }^{3}$, Garima Kalia ${ }^{4}$
}

\begin{abstract}
Background: There are a lot of questions in the mind of parents related to primary teeth. Various myths are also prevalent in the society about deciduous dentition. As a pediatric dentist, we come across various questions that are repeatedly asked, other than the chief complaint of the patient. No study has been conducted till date to address such queries. The current study highlights the major queries of parents related to their child's oral health.

Objectives: The purpose of the study is to evaluate the most frequently asked questions by aediatric patient's parents in day-to-day practice apart from the chief complaint and to compare the queries of urban and rural population.

Method: A sample size of 200 was taken for the study. Parents/attendants of the patients were given a questionnaire which consisted of queries of parents other than chief complain. The data were analyzed to find out what most of the parents want to know from a pediatric dentist about their child's dentition.

Results: Based on the survey, we were able to evaluate the most common questions about child's oral health and it was observed that there is a difference in the queries of parents among the rural and the urban population.

Conclusion: The role of a pediatric dentist is of the utmost importance in creating awareness among patients and their parents about oral health and the importance of primary teeth.

Keywords: Children, Paediatric dentist, Parents, Queries.

International Journal of Clinical Pediatric Dentistry (2019): 10.5005/jp-journals-10005-1598
\end{abstract}

\section{INTRODUCTION}

Pediatric dentists deal with the oral health of children from infancy through adolescence. Besides promoting the dental health of children, we also serve as an educational resource for parents. The parents' support and involvement in the child's oral health are important in influencing the dental health of the child. ${ }^{1}$ Cavities are not all that a pediatric patient's parents are worried about. There are a lot of other questions in their mind at a particular stage of their child's dental development; from newborn to teenage years.

Pediatric dentists play a dual role in the provision of professional preventive and therapeutic oral health care, which includes both primary and specialty care services. ${ }^{2}$ As a pediatric dentist, we come across various questions that are repeatedly asked, other than the chief complaint of the patient. Many parents are anxious about the unusual spacing; crowding and appearance of their child's teeth which we (pediatric dentists) believe are self-correcting. There are certain myths and taboos related to milk teeth in the society. Most of the time, we inherit these myths and hand them over to the next generation for example that too much brushing can harm the teeth or that milk teeth do not need care and treatment. ${ }^{3}$

There is a marked difference between the attitude of parents in the rural and the urban population regarding the oral health of children. The extent of initiation shown by the parents to know more about pediatric oral health seems greater in the urban population.

Over the years, there has been a lot of advancement in terms of science and technology in the dental health sector and mass media and Internet has evolved very much contributing to the awareness of people. Still, there are people who are ignorant toward their child's oral health. Most of the individuals do not bother to, or, perhaps, do not have the ability to go into the facts and logics. They still follow the old beliefs and customs of the society blindly. ${ }^{3}$ 1,3,4 Department of Pedodontics and Preventive Dentistry, Government
Dental College and Hospital, Jaipur, Rajasthan, India
2Department of Pediatric and Preventive Dentistry, Government Dental
College and Hospital, Jaipur, Rajasthan, India

Corresponding Author:Meenakshi Sharma, Department of Pedodontics and Preventive Dentistry, Government Dental College, Jaipur, Rajasthan, India, Phone: +91 8696860009, e-mail: dr.mesharma@gmail.com

How to cite this article: Rathore K, Tandon S, et al. Queries of Parents Related to their Children's Oral Health in Rural and Urban Area of Jaipur: A Clinical Study. Int J Clin Pediatr Dent 2019;12(2):88-91.

Source of support: Nil

Conflict of interest: None

Therefore, pediatric dentists should take a stand to bring a change in the society and, to initiate this change, we should have a gross idea of what people actually have in their minds. Till date, no study has been done to find out the queries of parents. The current study highlights the most common queries of people with regard to pediatric oral health.

\section{Study Design}

The present survey was conducted at the Department of Pediatric and Preventive Dentistry. A sample size of 200 children under 15 years of age and their parents/attendants were included in the study. The subjects were selected randomly from the outpatient Department of Pediatric Dentistry. Out of the 200 parents selected 100 were of rural background and 100 were of urban background. The study continued for 4 months during the period of May through August 2015. A structured questionnaire based on the most frequent questions asked by patients was also prepared.

o The Author(s). 2019 Open Access This article is distributed under the terms of the Creative Commons Attribution 4.0 International License (https://creativecommons. org/licenses/by-nc/4.0/), which permits unrestricted use, distribution, and non-commercial reproduction in any medium, provided you give appropriate credit to the original author(s) and the source, provide a link to the Creative Commons license, and indicate if changes were made. The Creative Commons Public Domain Dedication waiver (http://creativecommons.org/publicdomain/zero/1.0/) applies to the data made available in this article, unless otherwise stated. 
Parents/attendants of the patients were given a questionnaire to be filled to find out:

- What type of questions do parents have in their mind regarding the oral health of their children?

- What are the most frequently asked questions about child's dentition.

- Difference in the queries of the urban and rural population.

The data were analyzed using descriptive analysis to find out what most of the parents want to know from a pediatric dentist about their child's dentition.

\section{Results}

The present survey got an overwhelming response from the parents. All the 200 parents selected were interested in taking part in the survey. We got a lot of queries regarding child's oral health and based on the data collected from the survey, the following results were obtained (Table 1 ).

Table 2 shows the overall response of both the urban and rural population. Tables 3 and 4 show the questions which were asked most frequently by the urban and rural population, respectively.

Table 1: Questionnaire

\begin{tabular}{|c|c|c|}
\hline S. no. & Question & Remark \\
\hline 1. & $\begin{array}{l}\text { My child has broken teeth since birth. Are they } \\
\text { normal? }\end{array}$ & \\
\hline 2. & $\begin{array}{l}\text { Milk teeth anyway are going to fall, is it necessary } \\
\text { to get them treated? }\end{array}$ & \\
\hline 3. & $\begin{array}{l}\text { If a child's primary teeth are decayed or poorly } \\
\text { formed, will his permanent teeth also be faulty? }\end{array}$ & \\
\hline 4. & How can tooth decay be prevented? & \\
\hline 5. & At what age should a child start using a tooth brush? & \\
\hline 6. & Can decay be reversed by toothpaste? & \\
\hline 7. & Which toothpaste will be better for children? & \\
\hline 8. & $\begin{array}{l}\text { What are fluoride therapy and pit and fissure } \\
\text { sealant? }\end{array}$ & \\
\hline 9. & Does bottled milk cause decay? & \\
\hline 10. & Can breast feeding cause teeth to decay? & \\
\hline 11. & At what age should we see dentist first? & \\
\hline 12. & Adult teeth are coming in behind baby teeth & \\
\hline 13. & Child's lower front teeth are irregularly arranged & \\
\hline 14. & There is spacing between child's upper front teeth & \\
\hline 15. & What harm can irregular teeth do? & \\
\hline 16. & What is the proper age to correct irregular teeth? & \\
\hline 17. & There are white spots on child's permanent teeth & \\
\hline 18. & When does the first tooth erupt? & \\
\hline 19. & Which tooth is permanent? & \\
\hline 20. & $\begin{array}{l}\text { There are irregular bulges on cutting surface of } \\
\text { child's front teeth }\end{array}$ & \\
\hline 21. & Are children ill when teething? & \\
\hline 22. & $\begin{array}{l}\text { Should a primary tooth that is lost too soon be } \\
\text { replaced with a space maintainer? }\end{array}$ & \\
\hline 23. & Is thumb sucking harmful? & \\
\hline 24. & $\begin{array}{l}\text { What if child's tooth breaks accidentally due to fall } \\
\text { of trauma? }\end{array}$ & \\
\hline 25. & $\begin{array}{l}\text { Child's front adult teeth are too large, can we get } \\
\text { them trimmed? }\end{array}$ & \\
\hline
\end{tabular}

Table 2: Data collected from the survey

\begin{tabular}{|c|c|c|}
\hline S. no. & Question & Response (\%) \\
\hline 1. & $\begin{array}{l}\text { My child has broken teeth since birth. } \\
\text { Are they normal? }\end{array}$ & 15 \\
\hline 2. & $\begin{array}{l}\text { Milk teeth anyway are going to fall, is it } \\
\text { necessary to get them treated? }\end{array}$ & 41 \\
\hline 3. & $\begin{array}{l}\text { If a child's primary teeth are decayed or } \\
\text { poorly formed, will his permanent teeth also } \\
\text { be faulty? }\end{array}$ & 27 \\
\hline 4. & How can tooth decay be prevented? & 40 \\
\hline 5. & $\begin{array}{l}\text { At what age should a child start using a } \\
\text { tooth brush? }\end{array}$ & 5 \\
\hline 6. & $\begin{array}{l}\text { Can decay be reversed by toothpaste/ } \\
\text { medicine? }\end{array}$ & 24 \\
\hline 7. & Which toothpaste will be better for children? & 3 \\
\hline 8. & $\begin{array}{l}\text { What are fluoride therapy and pit and fissure } \\
\text { sealant? }\end{array}$ & 2 \\
\hline 9. & Does bottled milk cause decay? & 5 \\
\hline 10. & Can breast feeding cause teeth to decay? & 2 \\
\hline 11. & At what age should we see dentist first? & 6 \\
\hline 12. & Adult teeth are coming in behind baby teeth & 16 \\
\hline 13. & $\begin{array}{l}\text { Child's lower front teeth are irregularly } \\
\text { arranged }\end{array}$ & 21 \\
\hline 14. & $\begin{array}{l}\text { There is spacing between child's upper } \\
\text { front teeth }\end{array}$ & 15 \\
\hline 15. & What harm can irregular teeth do? & 5 \\
\hline 16. & $\begin{array}{l}\text { What is the proper age to correct irregular } \\
\text { teeth? }\end{array}$ & 4 \\
\hline 17. & $\begin{array}{l}\text { There are white spots on child's permanent } \\
\text { teeth }\end{array}$ & 15 \\
\hline 18. & When does the first tooth erupt? & 5 \\
\hline 19. & Which tooth is permanent? & 3 \\
\hline 20. & $\begin{array}{l}\text { There are irregular bulges on cutting surface } \\
\text { of child's front teeth }\end{array}$ & 9 \\
\hline 21. & Are children ill when teething? & 6 \\
\hline 22. & $\begin{array}{l}\text { Should a primary tooth that is lost too soon } \\
\text { be replaced with a space maintainer? }\end{array}$ & 2 \\
\hline 23. & Is thumb sucking harmful? & 4 \\
\hline 24. & $\begin{array}{l}\text { What if child's tooth breaks accidentally due } \\
\text { to fall of trauma? }\end{array}$ & 1 \\
\hline 25. & $\begin{array}{l}\text { Child's front adult teeth are too large, can we } \\
\text { get them trimmed? }\end{array}$ & 18 \\
\hline
\end{tabular}

There was a difference in the questions asked by parents from the urban and rural population. On the one hand, the most common question asked by the urban population was "How can tooth decay be prevented?" Out of the 100 parents interviewed, $24 \%$ raised their concern about the prevention of dental caries. The most common question asked by the rural population, on the other hand, was, "Milk teeth anyway are going to fall, is it necessary to get them treated?" A comparison of the most common queries of the urban and rural population was done, and it was found out that out of the 100 parents interviewed from the rural population, 35\% were ignorant toward the maintenance of primary teeth (Fig. 1).

\section{Discussion}

Knowledge is having the right answer but there would be no answers without questions. Thus, questions and queries are 
Table 3: Most common questions from the urban population

\begin{tabular}{lll}
\hline S. no. & Query & Percentage \\
\hline 1. & How can tooth decay be prevented? & 35 \\
2. $\quad \begin{array}{l}\text { If a child's primary teeth are decayed, will his } \\
\text { permanent teeth also be faulty? }\end{array}$ & 26 \\
3. $\quad \begin{array}{l}\text { Adult teeth are coming in behind baby teeth } \\
\text { 4. } \quad \begin{array}{l}\text { Child's front adult teeth are too large, can we } \\
\text { get them trimmed? }\end{array}\end{array}$ \\
$\begin{array}{l}\text { There are irregular bulges on cutting surface } \\
\text { of child's front teeth }\end{array}$ & 12 \\
6. $\quad \begin{array}{l}\text { My child has broken teeth since birth. } \\
\text { Are they normal? }\end{array}$ & 11 \\
7. $\quad \begin{array}{l}\text { There are white spots on child's permanent } \\
\text { teeth }\end{array}$ & 11 \\
\hline
\end{tabular}

Table 4: Most common questions from the rural population

\begin{tabular}{lll}
\hline S. no. & Query & Percentage \\
\hline 1. & $\begin{array}{l}\text { Milk teeth anyway are going to fall, is it } \\
\text { necessary to get them treated? }\end{array}$ & 64 \\
2. $\quad \begin{array}{l}\text { Can decay/cavity be reversed by toothpaste/ } \\
\text { medicine? }\end{array}$ & 43 \\
3. $\quad \begin{array}{l}\text { Child's front adult teeth are too large, can we } \\
\text { get them trimmed? }\end{array}$ & 24 \\
4. $\quad \begin{array}{l}\text { If a child's primary teeth are decayed or poorly } \\
\text { formed, will his permanent teeth also be faulty? }\end{array}$ & 21 \\
5. $\quad \begin{array}{l}\text { There are white spots on child's permanent } \\
\text { teeth }\end{array}$ & 19 \\
6. $\quad$ Adult teeth are coming in behind baby teeth & 10 \\
\hline
\end{tabular}

important. For us, the pediatric dentist, queries of patients and parents are an important means of providing improved dental care. Since the information obtained from the children is not always predictable, parents play an important role in providing valuable information regarding their child's oral health. Treating a small child mostly depends on one-to-three relationship, child, pedodontist, and family. This also has been represented by the pedodontic triangle as given by Wright.

Also, parents' dental fear plays a huge role in their child's fear of the dentist, since parents naturally transfer their fears of the world onto their young. So, catering to the queries of parents forms an integral part in providing empathetic and child-centered care. Communication among parents, dentists, and the child builds trust and confidence that last a lifetime. ${ }^{4-6}$

In the present study, $41 \%$ of the parents interviewed asked that since milk teeth will eventually fall, is it necessary to get them treated. These results are consistent with another study conducted by Bahuguna et al. according to which $65 \%$ of the caregivers believed that primary teeth need not be treated. ${ }^{7}$ There was a marked urban and rural variation in the results. About $64 \%$ of the parents from the rural population and $18 \%$ from the urban population had the query.

About $40 \%$ of the parents wanted to know how tooth decay can be prevented. Here also, the urban and the rural variation was observed. About $35 \%$ of the urban population asked the same, while only $5 \%$ of the rural population showed interest in the prevention of caries.

Such variations can be attributed to a variety of facts such as level of education, socioeconomic status, influence of society, and awareness toward oral health. ${ }^{7,8}$

Sometimes parents think that tooth decay is a reversible process and can be reversed by some medicine or toothpaste. ${ }^{9}$ In the present study, $24 \%$ of the parents including both rural and urban had the same view.

About $21 \%$ of the parents were concerned about the lower incisor crowding in their children. About $15 \%$ of the parents were worried about the spacing between maxillary central incisors during the ugly duckling stage. This finding was much less than a previous study done by Levy et al. ${ }^{10}$

About $6 \%$ of the parents asked whether children are ill during teething. The result was different from a previous study done by Nasir et al. in 2014 which proved that $65 \%$ of the parents think that children are ill during teething. ${ }^{3}$

Many a time, people responsible for the oral care of children believe that since primary teeth are anyway going to shed, it is not worth their while to spend time/money on providing good oral health to children. The onus of spreading this myth lies on many shoulders. Even in developed nations, most parents still take their children to the dentist for curative and not for preventive treatments. The present study highlights that there is a marked difference in the attitude of parents in the rural and the urban population regarding the oral health of the children. The extent of initiation shown by the parents in taking interest to know more

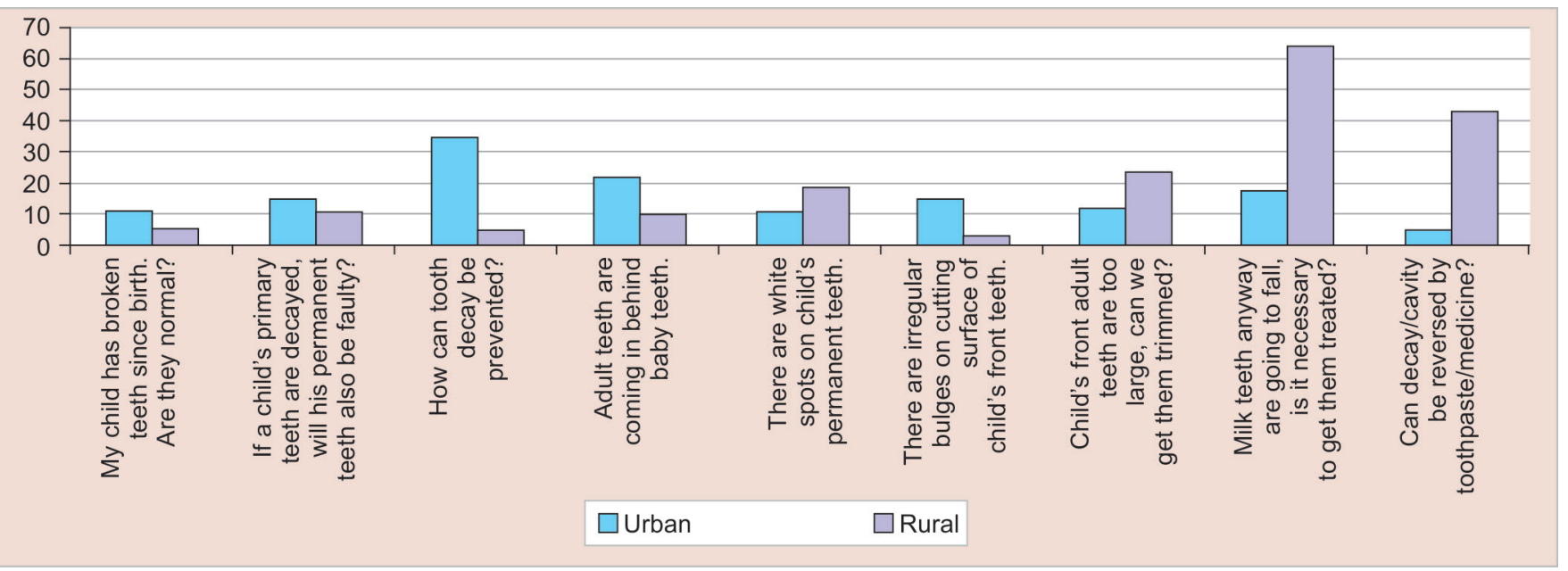

Fig. 1: Comparison of the queries of the urban and rural population 
about child oral health seems greater in the urban population. The rural population seem to be a little ignorant regarding the importance of maintaining primary dentition.

As a pediatric dentist, it is our responsibility to create awareness about the importance of primary teeth among parents as well as general dentists. Also, we should encourage parents to come up with their doubts regarding child oral health so that the myths about primary dentition can be eradicated and the bridge between a dentist and patients can be narrowed.

In recent years, there had been a paradigm shift from therapeutic to preventive dentistry. We as pediatric dental health providers should have more interactive sessions with the patient and parents rather than just catering to the symptomatic needs which will add newer perspectives to the overall health care services.

\section{Conclusion}

We, as pediatric dental health care professionals, need to create awareness among the population of our country about the significance of maintaining a healthy primary dentition and the attendant sequelae of not doing so. Answering the queries of patients and their parents form an integral part of providing a quality dental care. Having an idea of the possible queries of parents about oral health of their children will help in providing an effective treatment and will eradicate the myths about milk teeth in the society.

\section{References}

1. Kaur B. Evaluation of oral health awareness in parents of preschool children. Indian J Dent Res 2009;20(4):463-465. DOI: 10.4103/09709290.59455.

2. Policy on the Role of Pediatric Dentists as Both Primary and Specialty Care Providers. American Academy of Pediatric Dentistry 2013.

3. Nasir Z, Ahmed W, et al. Prevalence of Social Myths and Taboos Related To Dental Health Among General Population Of Rawalpindi - Pakistan. Pakistan Oral Dent J 2014;34(3):520-530.

4. Freeman R. Communicating with children and parents: recommendations for a child-parent-centred approach for paediatric dentistry. Eur Arch Paediatr Dent 2008;9(1):16-22.

5. Poutanenab R, Lahtiac $S$, et al. Parental influence on children's oral health-related behaviour. Acta Odontol Scand 2006;64(5):286-292. DOI: 10.1080/00016350600714498.

6. Barlow BS, Kanellis MJ, et al. Tooth eruption symptoms; a survey of parents and health professionals. ASDC J Dent Child 2002;69:148-150.

7. Bahuguna $R$, Jain $A$, et al. Knowledge and attitudes of parents regarding childdental care in an Indian population. Asian J Oral Health Allied Sci 2011;1(1):9-12.

8. Chhabra NS, Chhabra A.Parental knowledge, attitudes and cultural beliefs regarding oral health and dental care of preschool children in an Indian population: a quantitative study. Eur Arch Paediatr Dent 2012;13(2):76-82.

9. Setty JV, Srinivasan I. Awareness and attitude of patients' parentstoward pulp therapy of the primary teeth: aclinical survey. J Indian Soc Pedod Prev Dent 2011;29(3):198-201. DOI: 10.4103/0970-4388.85810.

10. Levy SM, Warren JJ. Factors associated with parents' esthetic perceptions of children's mixed dentition fluorosis and demarcated opacities. Pediatr Dent 2005;27(6):486-492. 